\title{
Facile synthesis of new thermally stable and organosoluble polyamide-imides based on non-coplaner phosphorus and silicon containing amines
}

\author{
SEEMA AGRAWAL and ANUDEEP KUMAR NARULA* \\ University School of Basic and Applied Sciences, Guru Gobind Singh Indraprastha University, \\ Sector-16C Dwarka, Delhi 110078, India \\ e-mail: researchchemlabb58@gmail.com
}

MS received 31 January 2014; revised 20 May 2014; accepted 24 May 2014

\begin{abstract}
Two new kinds of diamines, 3-[bis-(3-aminophenyl)-phosphinoyl)-phenyl]-3-(triphenylphosphoranylidene)-pyrrolidene-2,5-dione, (DAP) with phosphorus moiety and bis-(5-amino-naphthalene-1yl) dimethyl silane (DAS) with silicon moiety are synthesized. A series of novel aromatic polyamide-imides (PAIs) are prepared from three dicarboxylic acids and synthesized diamines. The phosphorus and silicon containing diamines and all polymers are characterized by FT-IR, NMR spectroscopic techniques and elemental analysis. The polymers obtained have good thermal stability and glass transition temperature $\left(\mathrm{T}_{\mathrm{g}}\right)$ in the range of $254-315^{\circ} \mathrm{C}$. All these novel polyamide-imides (PAIs) contain $10 \%$ weight loss at the temperature above $506^{\circ} \mathrm{C}$ and more than $59 \%$ residue at $600^{\circ} \mathrm{C}$ in nitrogen atmosphere. The resulting polymeric films exhibit high optical transparency and inherent viscosity in the range of 0.68 to $0.79 \mathrm{dL} / \mathrm{g}$. These polymers are found to be soluble in aprotic polar solvents such as NMP, DMSO, DMF and DMAc. Wide angle X-ray diffraction revealed that these polymers are predominantly amorphous in nature.
\end{abstract}

Keywords. Polyamide-imide; amine; thermal stability; flame retardancy; glass transition temperature.

\section{Introduction}

Polyimides are an essential class of engineering thermoplastic that possess advantageous physical properties such as high thermo oxidative property, solvent resistance, toughness, high modulus, chemical resistance and relatively low dielectric constant. ${ }^{1-6}$ These polymers are used in a variety of applications such as coatings, composites, adhesives, aerospace, optoelectronics and microelectronics. ${ }^{7-13}$ However, commercial use of these polymers is often limited due to their poor solubility in most organic solvents and their high softening or melting temperature. In order to overcome these limitations, various approaches to processable aromatic polyimides have focused on chemical modifications, mainly by preparing new monomers that provide less molecular order, better torsional mobility and low intermolecular interactions and improvement in solubility of polymers in organic solvents without sacrificing the above excellent properties. Some general approaches that have been commonly implemented, are incorporation of flexible linkages, attachment of bulky pendant substituents, use of asymmetric monomers,

*For correspondence non-coplanar biphenyl moiety and heteroaromatic rings into polyimide chains. ${ }^{14-22}$ Among various strategies adopted so far to improve processability of polyimides, insertion of an amide group in imide backbone has proven satisfactory. PAIs contain amide and cyclic imide units along the chain and hence inherit desirable characteristic balanced between those of polyimides and this class of polymers offer a good compromise between solubility, high thermal properties and processability. ${ }^{23-25}$

According to the phosphorylation technique first described by Yamazaki et al., a series of highmolecular-weight PAIs are synthesized from the imide ring bearing dicarboxylic acids with phosphorus and silicon containing new aromatic diamines. ${ }^{26}$ Introduction of silicon and its groups into polymeric chain is attractive for its significant improvement on the electrical properties, thermal stability and flame retardancy of polymers. ${ }^{27-29}$ Some other properties, such as high resistance to thermal oxidation and low toxicity are also observed for silicon containing compounds and polymers. ${ }^{30}$ The excellent thermal stability of silicon based polymers satisfies the requirements for application in advanced electronic industries. Silicon is therefore considered as one of the 'environment friendly' 
flame-retardant element, including phosphorus and nitrogen. ${ }^{31,32}$ Literature survey revealed that introduction of phosphorus into polymer backbone can largely improve the flame retardancy and also decrease the contamination of environment on pyrolysis. ${ }^{33}$ It has been proposed that phosphorus moiety decomposes at lower temperature relative to polymer matrix and forms a protective char layer over it and this char layer plays an important role in improving the flame retardancy of polymers. ${ }^{34,35}$

\section{Experimental}

\subsection{Materials}

5-Amino-naphthalene-1-ol (AN) and 2-(triphenyl phosphoranylidene) succinic anhydride (TPSA) all are purchased from Sigma Aldrich and used as received. Dichloro-dimethyl-silane (DDS) and glacial acetic acid are purchased from Merck and used without any purification. Pyridine $(\mathrm{CDH})$ is purified by distillation under reduced pressure over calcium hydride. Triphenyl phosphite (TPP, Merck) is used as received. Anhydrous calcium chloride is dried under reduced pressure at $150^{\circ} \mathrm{C}$ for $6 \mathrm{~h}$ prior to use. $\mathrm{N}$-methyl-2-pyrrolidone (NMP, Sigma Aldrich) is dried over phosphorus pentoxide for at least $15 \mathrm{~h}$ and distilled under reduced pressure. Methanol (Fisher Scientific) is received as HPLC grade solvent and used without purification. Tris (3-aminophenyl) phosphine oxide (TAPO) and all diimide-diacids are synthesized in our laboratory in the previous study. ${ }^{36}$ Structures of all dicarboxylic acids are shown below:

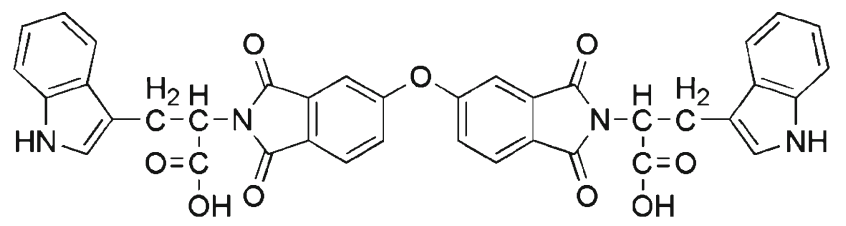

(O)

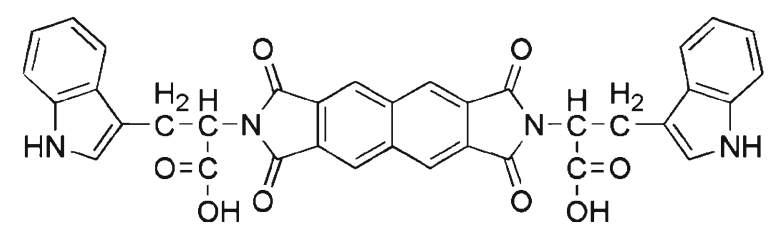

(N)

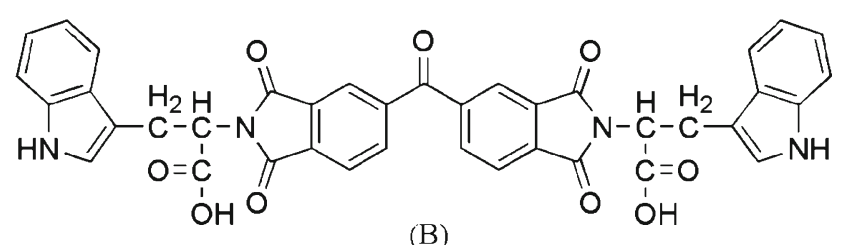

\subsection{Measurements}

FT-IR spectra are recorded on Perkin Elmer RXI spectrophotometer in the range $4000-400 \mathrm{~cm}^{-1}$. Elemental analysis is carried out by using GmbH VarioEL CHNS elemental analyser. NMR spectra are recorded on a BRUKER TOP-SPIN $300 \mathrm{MHz}$ spectrophotometer using DMSO- $d_{6}$ as a solvent and tetramethyl silane as an internal reference at room temperature. The inherent viscosity of the polymers is measured with an Ubbelohde viscometer at $30^{\circ} \mathrm{C}$. UV-visible spectra of the polymers in dilute $\mathrm{N}, \mathrm{N}$-dimethylformamide solution are recorded on Shimadzu UV-1601 UV-visible spectrophotometer. Differential scanning calorimetry (DSC) of the polymers is performed on TA 2100 thermal analyser having DSC 910 module with the heating rate of $10^{\circ} \mathrm{C} / \mathrm{min}$. in nitrogen atmosphere. Thermogravimetric data are obtained on a Perkin Elmer Diamond model at a heating rate of $10^{\circ} \mathrm{C} / \mathrm{min}$. in nitrogen atmosphere. $\mathrm{X}$-ray diffraction patterns of the polymers are obtained at room temperature on a Bruker Model D-8 Advance diffractometer with a scanning speed of $4 \% \mathrm{~min}$, and recorded in the $2 \theta$ range of $5-50^{\circ}$.

\subsection{Monomer synthesis}

2.3a Synthesis of 3-[bis-(3-aminophenyl)-phosphinoyl)phenyl]-3-(triphenyl-phosphoranylidene)-pyrrolidene2,5-dione $(\boldsymbol{D A P})$ : DAP is prepared according to scheme 1 . TPSA $(0.026 \mathrm{~mol})$ is dissolved in glacial acetic acid $(25 \mathrm{~mL})$ and TAPO $(0.026 \mathrm{~mol})$ is added. The solution is refluxed for $12 \mathrm{~h}$ and the resulting mixture is precipitated in ice cold water $(100 \mathrm{~mL})$, to give brown coloured solid. The precipitate is initially washed with water and then with aqueous sodium bicarbonate solution to remove acid content. The synthesized solid is dried in vacuum at $7^{\circ} \mathrm{C}$ for $5-6 \mathrm{~h}$ and recrystallized with chloroform to give pure compound. FT-IR $\left(\mathrm{KBr}, \mathrm{cm}^{-1}\right)$ : 3353 (N-H stretching), 2930 (aromatic C-H stretching), 1558 (aromatic C-C stretching), 1195 ( $\mathrm{P}=\mathrm{O}$ stretching), 1418 (P-Ar stretching), 1682 (imide $\mathrm{C}=\mathrm{O}$ stretching), 1375 (imide $\mathrm{C}-\mathrm{N}$ stretching). ${ }^{1} \mathrm{H}-\mathrm{NMR}, \delta$ (ppm, DMSO- $d_{6}, 300 \mathrm{MHz}$ ): 2.29 (s, $1 \mathrm{H}$, $\left.-\mathrm{CH}_{2}\right), 3.97$ (s, 2H, $\left.-\mathrm{NH}_{2}\right), 6.15$ (d, 1H, Ar-H), 6.28 (d, $1 \mathrm{H}, \mathrm{Ar}-\mathrm{H}), 6.81$ (s, 1H, Ar-H), 7.12 (t, 1H, Ar-H), 7.33 (d, 1H, Ar-H), $7.42(\mathrm{~m}, 1 \mathrm{H}, \mathrm{Ar}-\mathrm{H}) .{ }^{13} \mathrm{C}-\mathrm{NMR}, \delta$ (ppm, DMSO- $d_{6}, 300 \mathrm{MHz}$ ): 162.6 and 155.6 (C of imide $\mathrm{C}=\mathrm{O}$ ), 139.2 (aromatic $\mathrm{C}-\mathrm{NH}_{2}$ ), 138.9 (aromatic $\mathrm{C}$ attached to imide group), 132.6 and 131.3 (aromatic $\mathrm{C}$ $\mathrm{P}=\mathrm{O}$ ), 128.8 (aromatic $\mathrm{C}$ meta to $-\mathrm{NH}_{2}$ or $\mathrm{P}=\mathrm{O}$ ), 127.9 (aromatic $\mathrm{C}$ meta to $\mathrm{P}=\mathrm{O}$ or imide group), 127.4 (aromatic $\mathrm{C}$ of phosphoranylidene group), 126.6 (aromatic $\mathrm{C}$ ortho to $\mathrm{P}=\mathrm{O}$ or imide group), 124.8 (aromatic $\mathrm{C}$ 


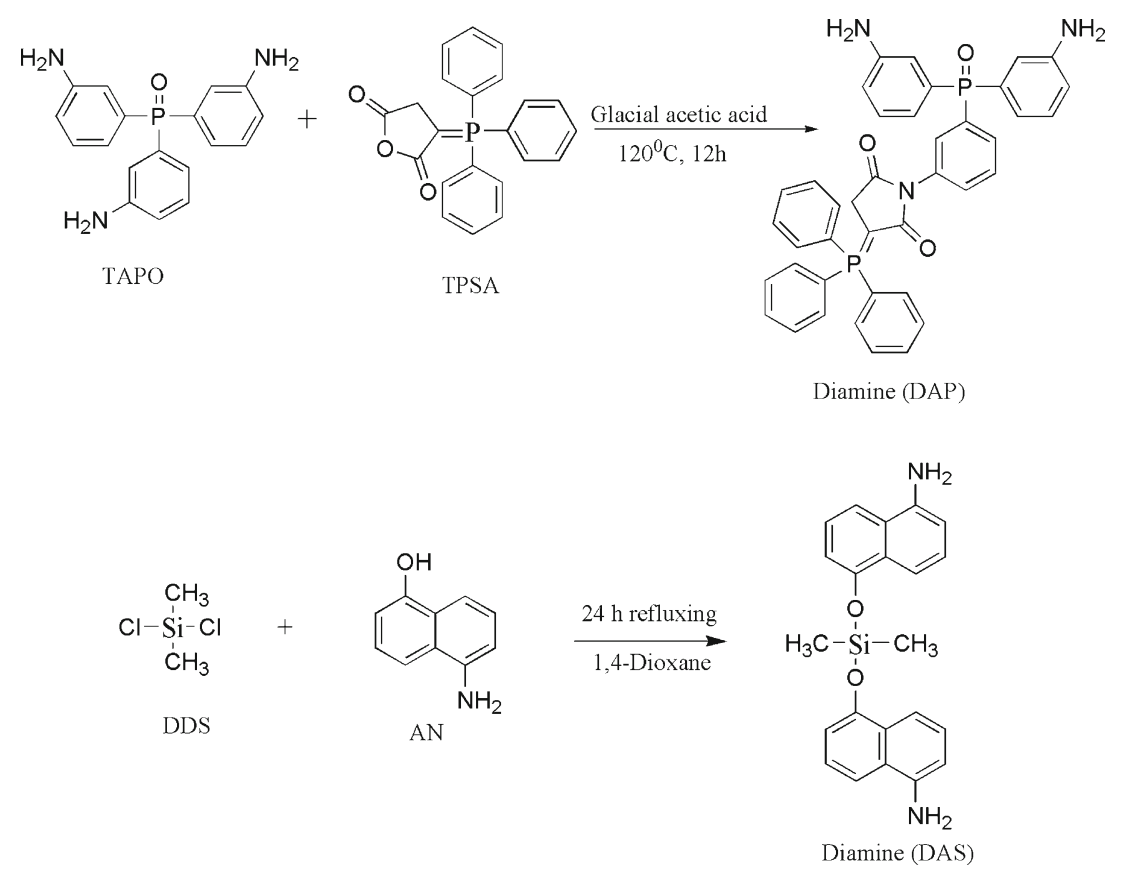

Scheme 1. Synthesis of phosphorus and silicon containing amines.

ortho to $\mathrm{P}=\mathrm{O}$ or para to imide group), 122.6 (aromatic $\mathrm{C}$ ortho to $\mathrm{P}=\mathrm{O}$ or para to $-\mathrm{NH}_{2}$ ), 121.1 (aromatic $\mathrm{C}$ ortho to imide group or para to $\mathrm{P}=\mathrm{O}$ ), 119.8 (aromatic $\mathrm{C}$ ortho to $-\mathrm{NH}_{2}$ or para to $\mathrm{P}=\mathrm{O}$ ), 117.3 (aromatic $\mathrm{C}$ ortho to $-\mathrm{NH}_{2}$ or $\left.\mathrm{P}=\mathrm{O}\right), 15.9\left(\mathrm{C}\right.$ of $\left.-\mathrm{CH}_{2}-\right)$.

2.3b Synthesis of bis-(5-amino-naphthalene-1-yl) dimethyl silane $(\boldsymbol{D A S}): \mathbf{A N}(0.05 \mathrm{~mol})$ is dissolved in 1,4-dioxane $(40 \mathrm{~mL})$ and introduced into $250 \mathrm{~mL}$ three necked flask equipped with mechanical stirrer, refluxed condenser and dry nitrogen inlet. The mixture was heated at $80^{\circ} \mathrm{C}$ under nitrogen atmosphere and stirred until the AN dissolved completely. DDS (0.025 mol) is added dropwise over a period of $1 \mathrm{~h}$ into the stirred solution and the mixture is refluxed for $24 \mathrm{~h}$ at $100^{\circ} \mathrm{C}$. A brown coloured precipitate is obtained which is filtered and washed with 1,4-dioxane. The crude is dried at $70^{\circ} \mathrm{C}$ under vacuum for overnight.FT-IR $\left(\mathrm{KBr}, \mathrm{cm}^{-1}\right)$ : $3378(\mathrm{~N}-\mathrm{H}$ stretching), $1610(\mathrm{~N}-\mathrm{H}$ flexion), 1540 (aromatic C-C stretching), 3018 (aromatic C-H stretching), 1250 (aromatic C-O stretching), 1310 (Si- C), 1050 (Si-O). ${ }^{1} \mathrm{H}-\mathrm{NMR}, \delta$ (ppm, DMSO- $d_{6}$, $300 \mathrm{MHz}): 1.39$ (s, 3H, Si-CH $), 3.98\left(\mathrm{~s},-\mathrm{NH}_{2}\right), 6.34$ (t, 1H, Ar-H), 6.45 (d, 1H, Ar-H), $6.82(\mathrm{~d}, 1 \mathrm{H}, \mathrm{Ar}-\mathrm{H})$, 7.12 (d, 1H, Ar-H), 7.88 (t, 1H, Ar-H), $9.32(\mathrm{~d}, 1 \mathrm{H}$, Ar-H). ${ }^{13} \mathrm{C}-\mathrm{NMR}, \delta$ (ppm, DMSO- $d_{6}, 300 \mathrm{MHz}$ ): -1.8 $\left(\mathrm{Si}-\mathrm{CH}_{3}\right), 118.2$ (aromatic C ortho to $\left.-\mathrm{NH}_{2}\right), 119.6$ (aromatic $\mathrm{C}$ linked to -O-Si), 121.4 (aromatic C para to $-\mathrm{NH}_{2}$ ), $128.2 \& 130.1$ (aromatic $\mathrm{C}$ connecting benzene ring), 136.2 (aromatic C meta to $-\mathrm{NH}_{2}$ ), 148.4 (aromatic C-NH $\mathrm{NH}_{2}$ ), 157.3 ((aromatic C-O-Si).

\subsection{Polymer synthesis}

A typical example of TPP-activated polycondensation of polymer synthesis is shown in scheme 2 and described as follows. A mixture of DIDA (1mmol) and aromatic amine $(1 \mathrm{mmol})$, anhy. $\mathrm{CaCl}_{2}(0.30 \mathrm{~g})$, TPP $(2.3 \mathrm{~mL})$ and pyridine $(2.3 \mathrm{~mL})$ in NMP $(16 \mathrm{~mL})$ is stirred at $110^{\circ} \mathrm{C}$ for $4 \mathrm{~h}$ in a $25 \mathrm{~mL}$ flask. The viscosity of the reaction solution is increased after $1 \mathrm{~h}$; therefore an additional volume of NMP is added to carry out the reaction in homogeneous medium. At the end of the reaction, the polymer solution is poured slowly into methanol $(250 \mathrm{~mL})$ with stirring, to give a fibre-like precipitate which is washed thoroughly with hot water and methanol, filtered and dried in vacuum at $120^{\circ} \mathrm{C}$.

All the polyamide-imides are synthesized by similar procedure.

\section{Results and Discussion}

\subsection{Monomer synthesis and characterization}

Silicon and phosphorus containing diamines are synthesized according to scheme 1 and their structures are confirmed by spectroscopic techniques and elemental analysis. The physical characterization and elemental data are shown in table 1.

Figure 1 represents the FT-IR spectrum of diamine, DAS. This spectrum shows the characteristic absorption bands at $3378 \mathrm{~cm}^{-1}$ (N-H stretching of $-\mathrm{NH}_{2}$ group), $1540 \mathrm{~cm}^{-1}$ (aromatic C-C stretching), $1310 \mathrm{~cm}^{-1}$ (Si-C 


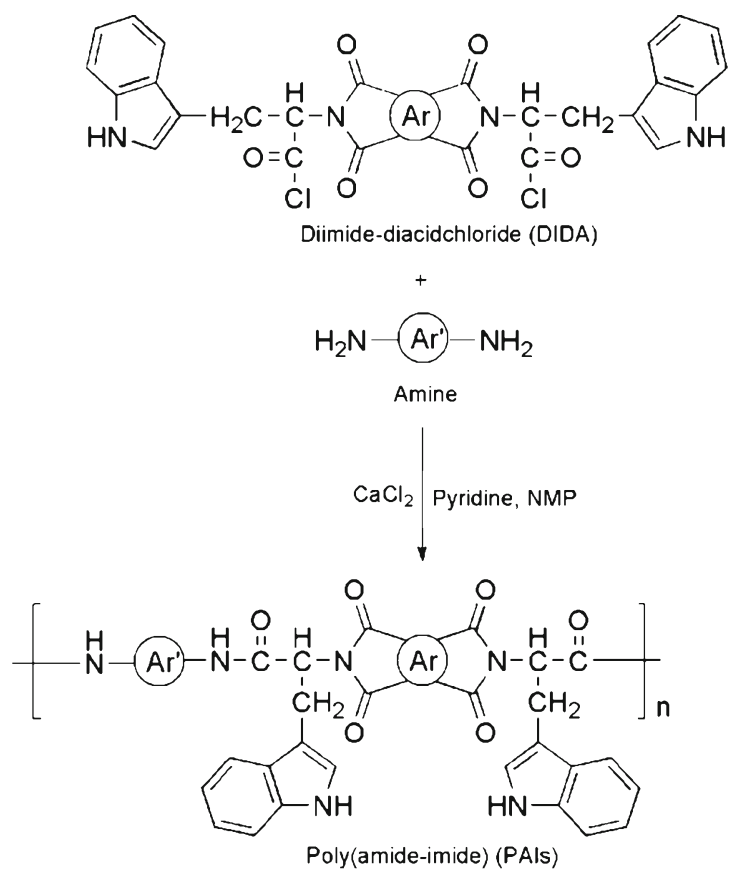

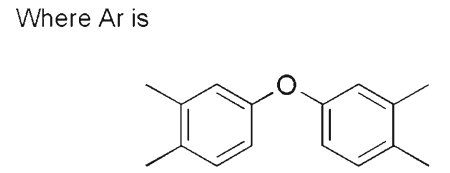

(O)<smiles>Cc1cccc(P(=O)(c2cccc(C)c2)c2cccc(N3C(=O)CC(=P(c4ccccc4)(c4ccccc4)c4ccccc4)C3=O)c2)c1</smiles>

(DAP)<smiles>Cc1cc2cc(C)c(C)cc2cc1C</smiles>

$(\mathrm{N})$<smiles>Cc1ccc(C(=O)c2ccc(C)c(C)c2)cc1C</smiles>

(B)

Scheme 2. Synthesis of polyamide-imides.

stretching) and $1050 \mathrm{~cm}^{-1}$ due to Si-O stretching. The absorption band at $1250 \mathrm{~cm}^{-1}$ appears due to aromatic C-O stretching of ether group. As shown in figure 2, the ${ }^{1} \mathrm{H}-\mathrm{NMR}$ spectrum of diamine, DAS presented signals in downfield region around 6.34-9.32 ppm due to Ar-H protons. A singlet is obtained at $3.98 \mathrm{ppm}$ due to $-\mathrm{NH}_{2}$ protons. In addition, a chemical shift is observed at $1.39 \mathrm{ppm}$, and this is attributed to the $\mathrm{CH}_{3}$ protons linked to $\mathrm{Si}$ atom. Figure 3 shows the ${ }^{13} \mathrm{C}-\mathrm{NMR}$ spectrum of diamine, DAS. In this spectrum,

Table 1. Physical characteristics and elemental analysis data of monomers.

\begin{tabular}{|c|c|c|c|c|c|c|c|c|}
\hline $\begin{array}{l}\text { Sample } \\
\text { Designation }\end{array}$ & Color & Yield & $\begin{array}{l}\text { Molecular } \\
\text { Formula }\end{array}$ & $\begin{array}{l}\text { Molecular } \\
\text { Weight }\end{array}$ & & Elemental \% C & analysis $\% \mathrm{H}$ & $\% \mathrm{~N}$ \\
\hline DAP & Brown & 99.2 & $\mathrm{C}_{40} \mathrm{H}_{33} \mathrm{~N}_{3} \mathrm{O}_{3} \mathrm{P}_{2}$ & 665.66 & Calcd. Found & 72.1772 .67 & 5.004 .55 & 6.316 .67 \\
\hline DAS & Black & 88.9 & $\mathrm{C}_{22} \mathrm{H}_{22} \mathrm{~N}_{2} \mathrm{O}_{2} \mathrm{Si}$ & 374.51 & Calcd. Found & 70.5669 .98 & 5.925 .61 & 7.487 .04 \\
\hline
\end{tabular}




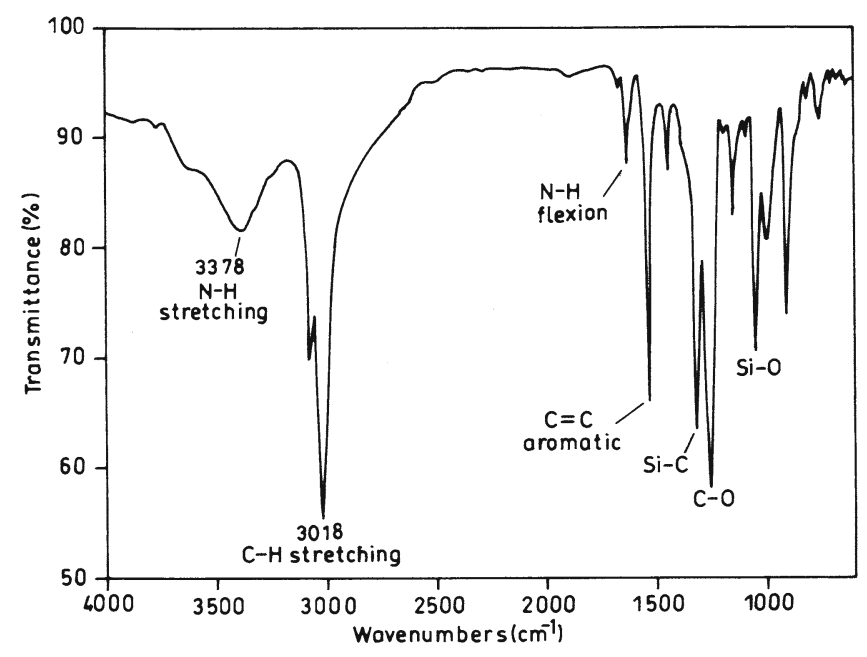

Figure 1. FT-IR spectrum of DAS.

carbon of methyl group is observed at $-1.8 \mathrm{ppm}$. All aromatic carbons appeared in the range of 118.2-157.3 ppm and the carbon attached to $-\mathrm{NH}_{2}$ group appeared at $148.4 \mathrm{ppm}$. Similar spectra are obtained for diamine, DAP.

\subsection{Polymer synthesis and characterization}

The imide ring containing diimide-diacids, phosphorus and silicon containing diamines with phenyl moieties are established as potential monomers for the synthesis of polyamide-imides, capable of imparting high

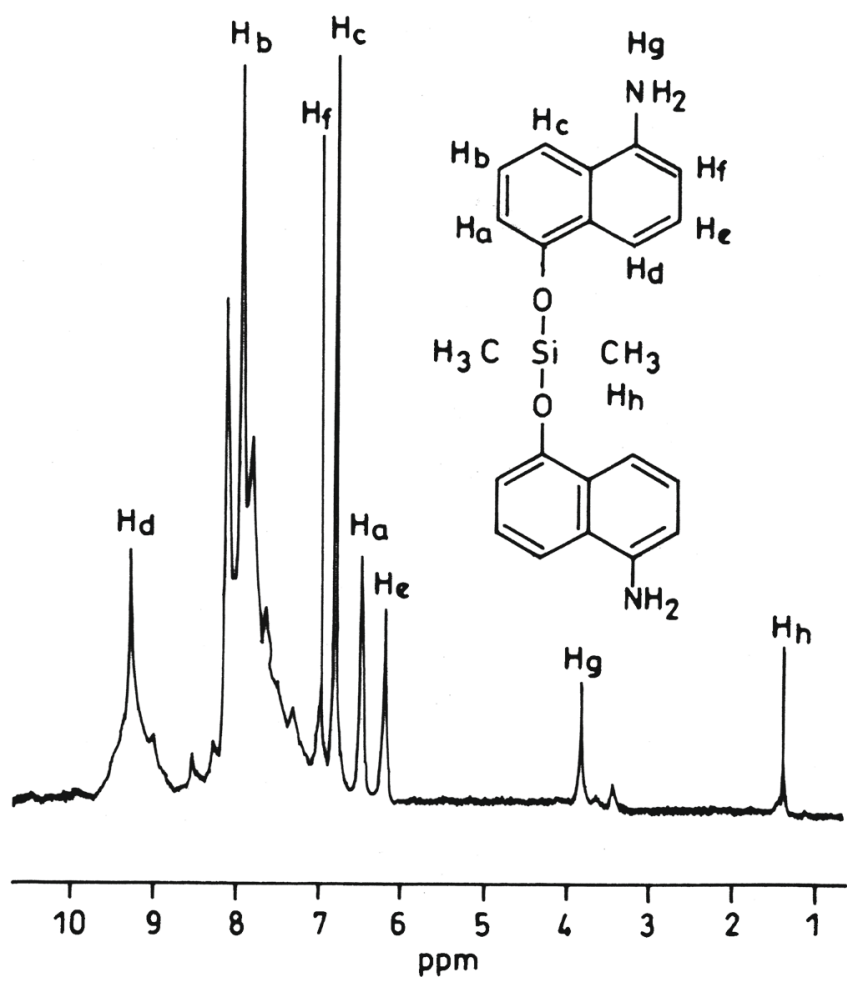

Figure 2. ${ }^{1} \mathrm{H}-\mathrm{NMR}$ spectrum of DAS. thermal stability and good processability. The synthesized polymers are insoluble in either chloroform or tetrahydrofuran (THF), even on heating. Hence their molecular weight distribution (MWD) cannot be determined by GPC. ${ }^{37}$ The inherent viscosities of these polymers are recorded in the range of 0.68 to $0.79 \mathrm{dL} / \mathrm{g}$ and all data are summarized in table 2 . The higher value of inherent viscosity indicated the formation of high molecular weight polymers, which may be due to the high reactivity of diamines used to synthesize polymers.

All the synthesized polymers are characterized by FT-IR, NMR spectroscopic techniques and elemental analysis. The elemental data of resulting polyamideimides agreed well with the calculated values, given in table 2. Figure 4 shows the FT-IR spectrum of polymer, DAP/B. This spectrum shows N-H stretching frequency due to the amide group as a broad band at $3377 \mathrm{~cm}^{-1}$. The amide band associated with the stretching vibration of the carbonyl group, appeared around $1726 \mathrm{~cm}^{-1}$ (symmetrical stretching), $1780 \mathrm{~cm}^{-1}$ (asymmetrical stretching) and imide ring deformation around $763 \mathrm{~cm}^{-1}$, together with some absorption bands around 1410 and $1209 \mathrm{~cm}^{-1}$ due to $\mathrm{P}-\mathrm{Ar}$ and $\mathrm{P}-\mathrm{O}$ stretching respectively. A representative ${ }^{1} \mathrm{H}-\mathrm{NMR}$ spectrum of polymer, DAP/B is shown in figure 5 which is in good agreement with the polymer structure. This spectrum shows characteristic resonance signals of aromatic protons in the region of 6.72-9.14 ppm and a signal at $10.2 \mathrm{ppm}$ due to $-\mathrm{NH}$ of pyrrole ring. In addition, a characteristic signal is also obtained at $8.17 \mathrm{ppm}$ due to $-\mathrm{CONH}$ proton.

\subsection{Polymer properties}

3.3a Solubility of polymers in organic solvents: The solubility of all the polymers is investigated qualitatively in various organic solvents and the results are tabulated in table 3. All the PAIs show higher solubility in polar aprotic solvents like DMF, DMSO, DMAc, NMP, pyridine and m-cresol. These polymers are still not soluble in common organic solvents such as THF, chloroform and toluene even at a high temperature due to low value of dielectric constant of solvents. These results show that the synthesized PAIs have characteristic solubility. However, the incorporation of oxyphenyl linkage, benzophenone group, naphthalene moiety and laterally attached bulky $(\mathrm{Ph})_{3} \mathrm{P}$ group as well as $\mathrm{Si}-\mathrm{O}-\mathrm{Ph}$ linkage reduce intermolecular interaction between the polymer chain and rigidity. The solubility of polymers is greatly enhanced by the presence of non-coplaner and twist heterocyclic moiety in polymer backbone and also due to incorporation of phosphine oxide moiety. ${ }^{38}$ 


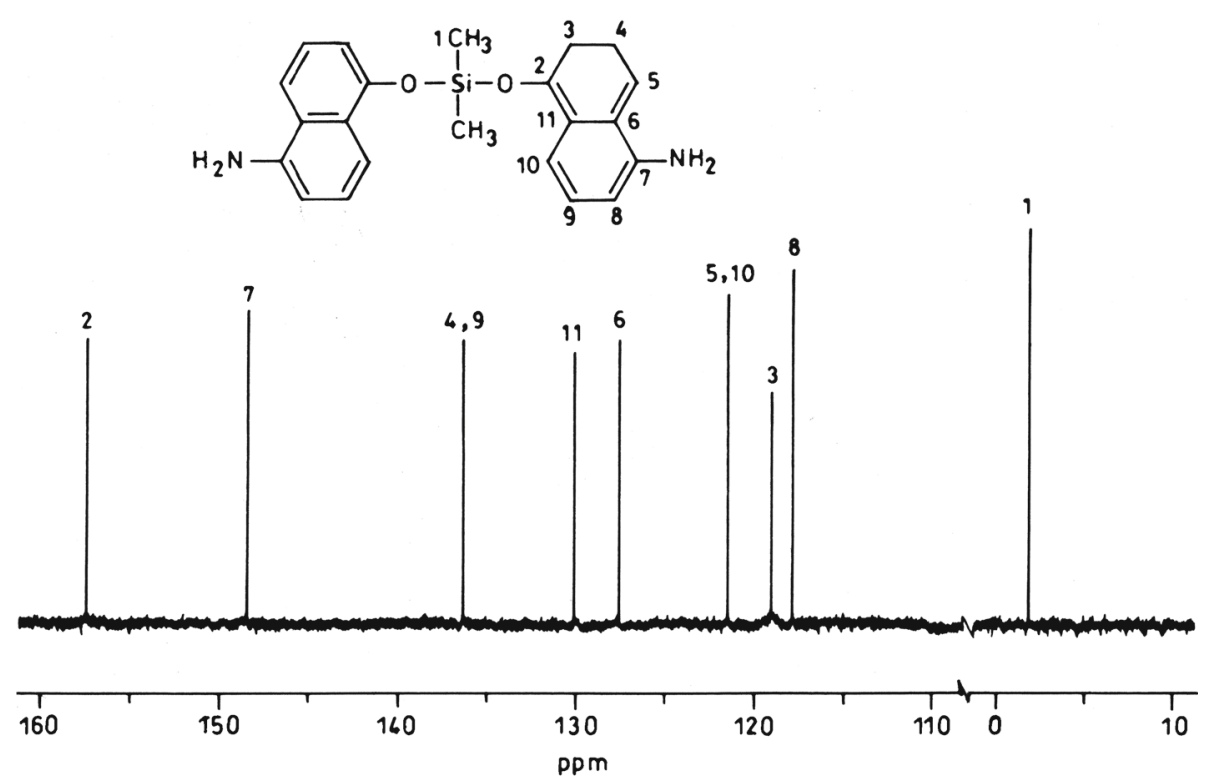

Figure 3. ${ }^{13} \mathrm{C}-\mathrm{NMR}$ spectrum of DAS.

Table 2. Inherent viscosities and elemental analysis data of polyamide-imides.

\begin{tabular}{lccccccc}
\hline $\begin{array}{l}\text { Sample } \\
\text { designation }\end{array}$ & $\eta_{\text {inh }}(\mathrm{dL} / \mathrm{g})^{\mathrm{a}}$ & $\begin{array}{c}\text { Molecular } \\
\text { formula }\end{array}$ & $\begin{array}{c}\text { Formula } \\
\text { weight }\end{array}$ & Elemental & $\begin{array}{c}\text { Analysis } \\
\mathrm{C}(\%)\end{array}$ & $\mathrm{H}(\%)$ & $\mathrm{N}(\%)$ \\
\hline DAP/O & 0.74 & $\left(\mathrm{C}_{82} \mathrm{H}_{65} \mathrm{~N}_{7} \mathrm{O}_{10} \mathrm{P}_{2}\right)_{\mathrm{n}}$ & $(1370)_{\mathrm{n}}$ & Calcd. Found & 71.8771 .56 & 4.784 .84 & 7.157 .37 \\
DAP/N & 0.68 & $\left(\mathrm{C}_{80} \mathrm{H}_{63} \mathrm{~N}_{7} \mathrm{O}_{9} \mathrm{P}_{2}\right)_{\mathrm{n}}$ & $(1328)_{\mathrm{n}}$ & Calcd. Found & 72.3371 .95 & 4.784 .59 & 7.386 .99 \\
DAP/B & 0.76 & $\left(\mathrm{C}_{83} \mathrm{H}_{65} \mathrm{~N}_{7} \mathrm{O}_{10} \mathrm{P}_{2}\right)_{\mathrm{n}}$ & $(1382)_{\mathrm{n}}$ & Calcd. Found & 72.1171 .88 & 4.744 .97 & 7.097 .38 \\
DAS/O & 0.78 & $\left(\mathrm{C}_{64} \mathrm{H}_{54} \mathrm{~N}_{6} \mathrm{O}_{9} \mathrm{Si}\right)_{\mathrm{n}}$ & $(1079)_{\mathrm{n}}$ & Calcd. Found & 71.2371 .56 & 5.044 .87 & 7.797 .89 \\
DAS/N & 0.79 & $\left(\mathrm{C}_{62} \mathrm{H}_{52} \mathrm{~N}_{6} \mathrm{O}_{8} \mathrm{Si}\right)_{\mathrm{n}}$ & $(1037)_{\mathrm{n}}$ & Calcd. Found & 71.8071 .64 & 5.055 .47 & 8.108 .36 \\
DAS/B & 0.73 & $\left(\mathrm{C}_{65} \mathrm{H}_{54} \mathrm{~N}_{6} \mathrm{O}_{9} \mathrm{Si}\right)_{\mathrm{n}}$ & $(1091)_{\mathrm{n}}$ & Calcd. Found & 71.5471 .75 & 4.995 .15 & 7.707 .58 \\
\hline
\end{tabular}

${ }^{\mathrm{a}}$ Measured in DMF at $30^{\circ} \mathrm{C}$ at a concentration of $0.5 \mathrm{~g} / \mathrm{dL}$

3.3b DSC measurements: Differential scanning calorimetry (DSC) is used to determine the $\mathrm{T}_{\mathrm{g}}$ of all polymers at a heating rate of $10^{\circ} \mathrm{C} \mathrm{min}-1$ in nitrogen atmosphere. DSC curves of polymers DAP/N and

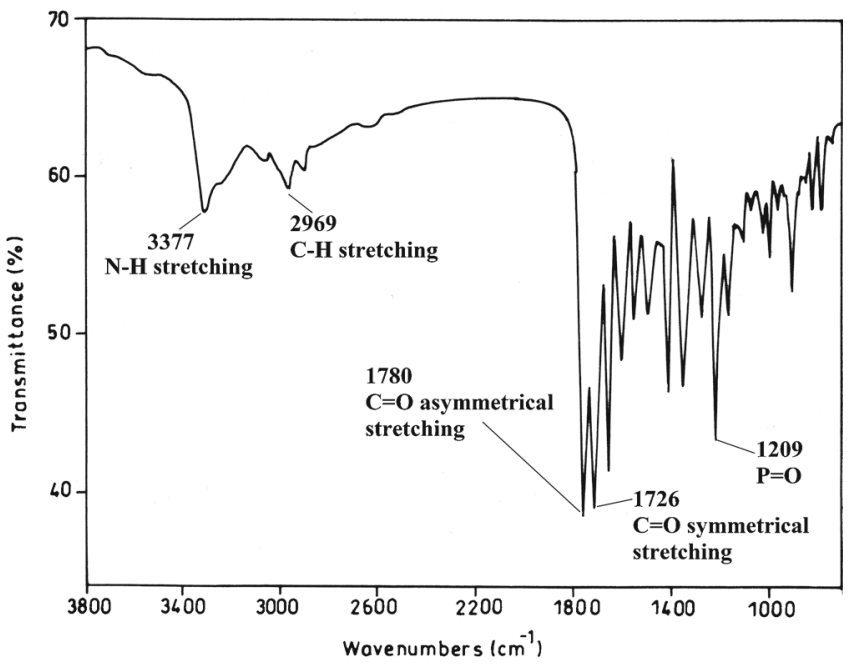

Figure 4. FT-IR spectrum of DAP/B.
DAS/N are represented in figure 6 and all data are given in table 4 . The $\mathrm{T}_{\mathrm{g}}$ values are read at the middle of the first breakdown observed in DSC curves, and found in the range $254-315^{\circ} \mathrm{C}$. The glass transition temperature of polymers depends on the structure of diamine and dianhydride component of diimidediacids, and decreases with increasing flexibility of polymeric backbone. It is observed that the $\mathrm{T}_{\mathrm{g}}$ value of silicon containing polymers is lower than the polymers having phosphorus containing phenyl moiety which may be due to the flexible linkage of Si-O-Ph backbone in polymer. Incorporation of Si would result in polymers with bulk pendants and these bulk pendants may simultaneously increase the free volume and reduce the cross-linking density of the polymers, to lower the $\mathrm{T}_{\mathrm{g}} \cdot{ }^{39}$ The $\mathrm{T}_{\mathrm{g}}$ value of DAP based polymers is also low due to the bulky and non-coplaner triphenyl phosphoranylidene group which increase the intermolecular distance that triphenyl phosphine oxide group is not rigid conjugate structure but rather a flexible structure which is convenient to molecular motion and formation of $\mathrm{T}_{\mathrm{g}}$. Therefore, triphenyl phosphoranylidene and 


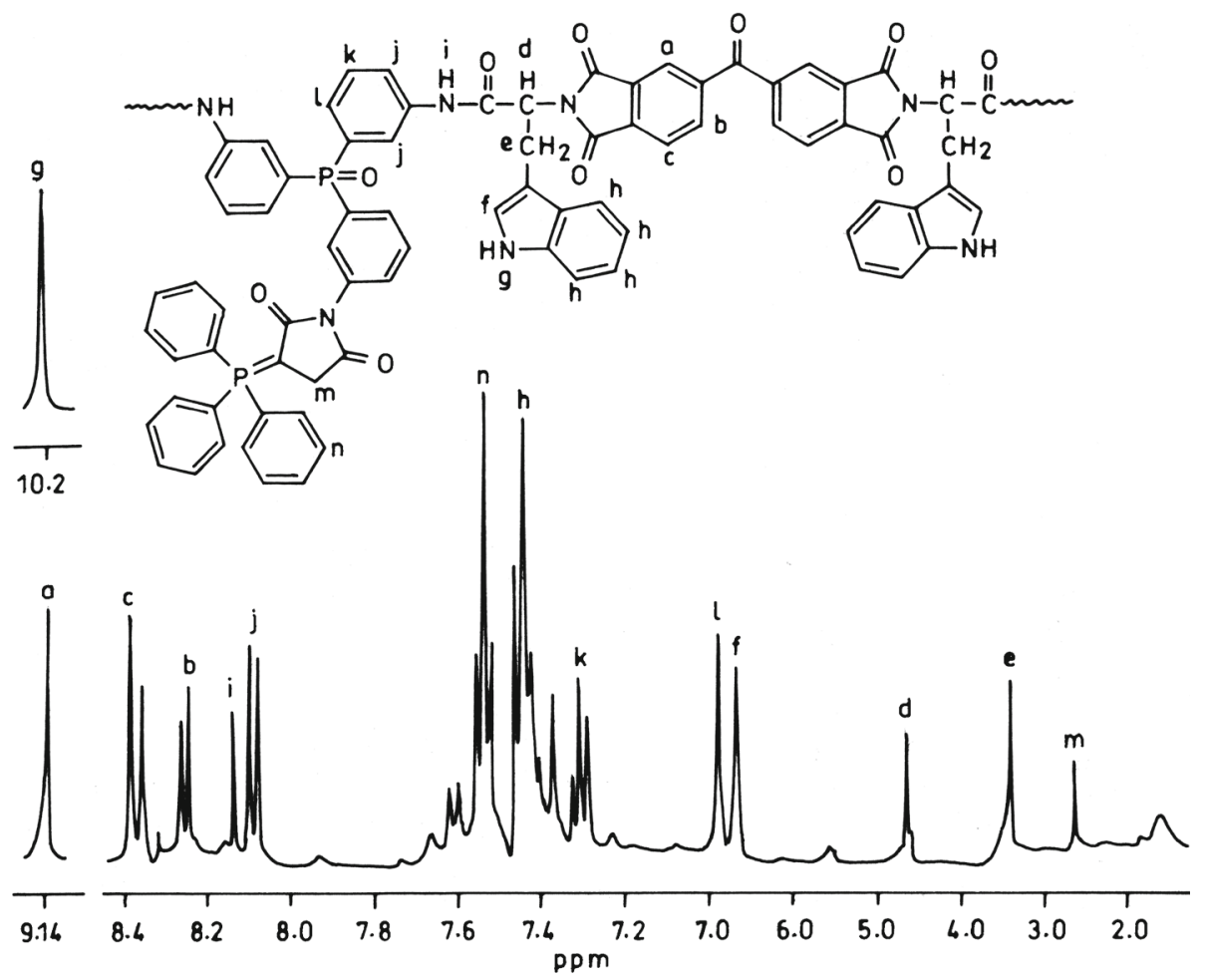

Figure 5. $\quad{ }^{1} \mathrm{H}-\mathrm{NMR}$ spectrum of DAP/B.

Table 3. Solubility of polyamide-imides in organic solvents.

\begin{tabular}{lcccccccccc}
\hline Polymer & NMP & DMF & Acetone & THF & DMSO & m-Cresol & Pyridine & Chloroform & $\mathrm{H}_{2} \mathrm{SO}_{4}$ & DMAc \\
\hline DAP/O & ++ & ++ & + & - & ++ & ++ & ++ & - & ++ & ++ \\
DAP/N & ++ & ++ & + & - & ++ & ++ & + & - & ++ & ++ \\
DAP/B & ++ & ++ & + & - & ++ & ++ & ++ & - & ++ & ++ \\
DAS/O & ++ & ++ & - & - & ++ & ++ & ++ & - & ++ & ++ \\
DAS/N & ++ & ++ & - & - & ++ & ++ & + & - & ++ & ++ \\
DAS/B & ++ & ++ & - & - & ++ & ++ & ++ & - & ++ & ++ \\
\hline
\end{tabular}

$(++)$ highly soluble, $(+)$ sparingly soluble, (-) insoluble

DMF:N,N-dimethyl formamide, THF:tetrahydrofuran, DMSO:dimethyl sulphoxide, NMP: N-methyl-2-pyrrolidone, $\mathrm{H}_{2} \mathrm{SO}_{4}$ :sulphuric acid, $\mathrm{H}_{2} \mathrm{O}$ :water, DMAc:N,N-dimethyl acetamide

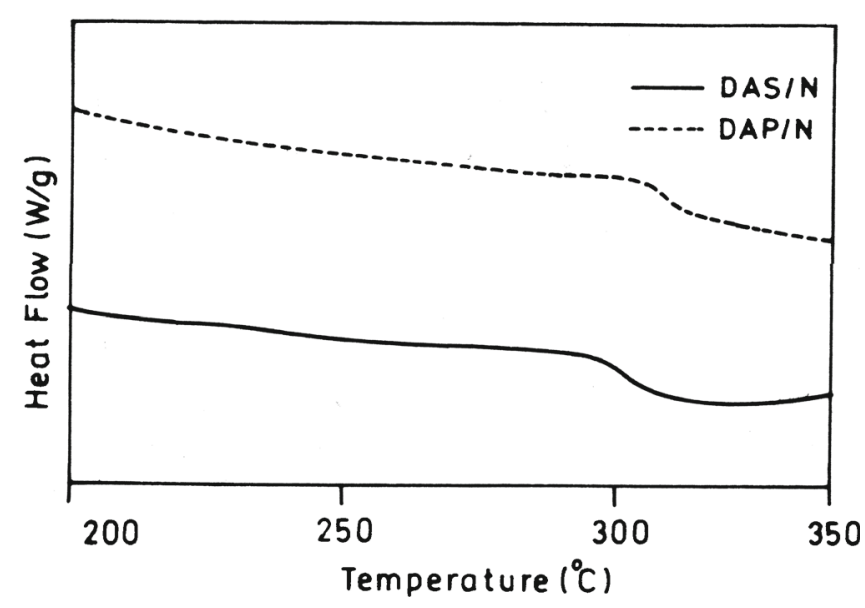

Figure 6. DSC scans of polymer (a) DAP/N and (b) $\mathrm{DAS} / \mathrm{N}$ at heating rate of $10^{\circ} \mathrm{C} / \mathrm{min}$ under nitrogen atmosphere. triphenyl phosphine oxide moiety in polymeric chain can provide motion space to groups and make the $\mathrm{T}_{\mathrm{g}}$ of polymers decrease. ${ }^{40}$

Consequently, higher $\mathrm{T}_{\mathrm{g}}$ value of polymer, DAP/N and $\mathbf{D A S} / \mathbf{N}$ can also be observed due to incorporation of rigid and kinked naphthalene units in polymeric backbone. However, in addition to diimide-diacids, the values of $\mathrm{T}_{\mathrm{g}}$ shows the order $\mathbf{N}>\mathbf{B}>\mathbf{O}$ as illustrated in table 4.

3.3c Thermal stability: The thermal properties of the resulting polyamide-imides are investigated by TGA at the heating rate of $10^{\circ} \mathrm{C} \mathrm{min}{ }^{-1}$ in nitrogen atmosphere. The TG curves of polymers DAP/N and DAS/N are shown in figure 7. All data of initial decomposition temperature (IDT), temperature for $10 \%$ weight loss 
Table 4. The thermal properties of polyamide-imides.

\begin{tabular}{lccccc}
\hline Polymer & $\mathrm{IDT}^{\mathrm{a}(}\left({ }^{\circ} \mathrm{C}\right)$ & $\mathrm{T}_{\mathrm{d}} 10 \%{ }^{\mathrm{b}}\left({ }^{\circ} \mathrm{C}\right)$ & Char Yield $(\%)$ & $\mathrm{T}_{\circ}^{\mathrm{d}}\left({ }^{\circ} \mathrm{C}\right)$ & $\mathrm{T}_{\mathrm{g}}^{\mathrm{e}}\left({ }^{\circ} \mathrm{C}\right)$ \\
\hline DAP/O & 456 & 506 & 67 & 267 & 274 \\
DAP/N & 489 & 561 & 63 & 309 & 315 \\
DAP/B & 462 & 517 & 65 & 263 & 268 \\
DAS/O & 498 & 564 & 62 & 249 & 256 \\
DAS/N & 522 & 575 & 59 & 298 & 302 \\
DAS/B & 510 & 557 & 61 & 248 & 254
\end{tabular}

$\overline{{ }^{a}}$ Initial decomposition temperature, determined by TGA in $\mathrm{N}_{2}$ atmosphere at a heating rate of $10^{\circ} \mathrm{C} / \mathrm{min}$

b Temperature of $10 \%$ weight loss, determined by TGA in $\mathrm{N}_{2}$ atmosphere at a heating rate of $10^{\circ} \mathrm{C} / \mathrm{min}$

${ }^{c}$ Residual weight $\%$ at $600^{\circ} \mathrm{C}$ in nitrogen

d Onset temperature from DSC measurements in $\mathrm{N}_{2}$, defines the point at which the first deviation from the baseline on the low temperature side is observed

${ }^{\mathrm{e}}$ Glass transition temperatures from the DSC traces in $\mathrm{N}_{2}$ at heating rate of $10^{\circ} \mathrm{C} / \mathrm{min}$

$\left(\mathrm{T}_{\mathrm{d} 10 \%}\right)$ and weight residue at $600^{\circ} \mathrm{C}$ of all polymers are summarized in table 4 . The IDT and temperature for $10 \%$ weight loss in nitrogen stay within the range of $456-522^{\circ} \mathrm{C}$ and $506-575^{\circ} \mathrm{C}$ respectively, which are the main criteria to determine thermal stability of polymers. The amount of carbonized residue (char yield) of these polymers is found in the range $59-67 \%$ at $600^{\circ} \mathrm{C}$. The IDT of DAP based polymer is slightly lower than DAS based polymers, owing to the less strength of phosphorus bonds in polymers, and hence decompose at low temperature. The char yield of phosphorus containing polymers is higher even if they have low IDT and thus, phosphorus in polymeric chain can enhance polymer charring property during combustion. Thus, it can be deduced that triphenyl phosphoranylidene and triphenyl phosphine oxide structure have a synergistic effect and can promote materials to form strong char layer. The char yield of silicon containing polymers is also

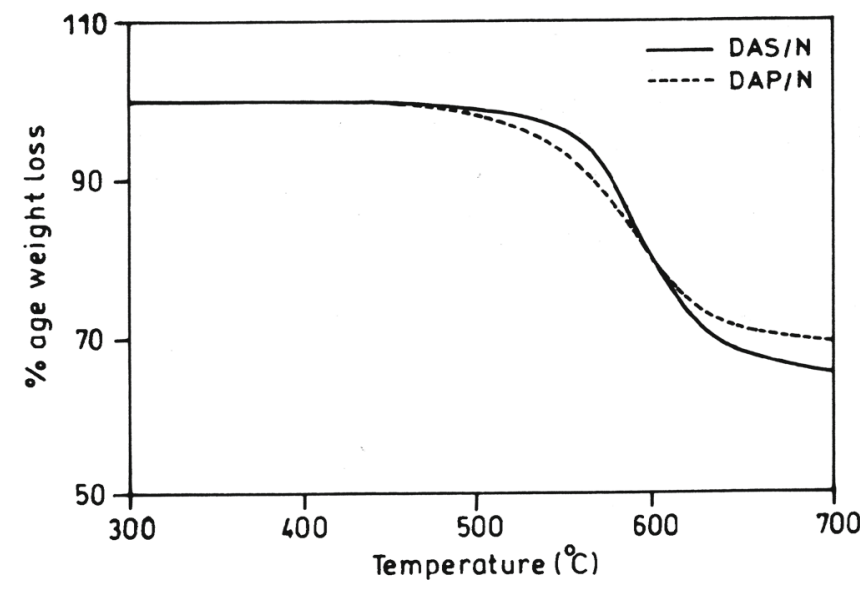

Figure 7. TGA of polymer (a) DAP/N and (b) DAS/N at heating rate of $10^{\circ} \mathrm{C} / \mathrm{min}$ under nitrogen atmosphere. high but slightly less than polymers with phosphorus moiety. The incorporation of silicon in polymeric chain also enhances the char formation and protects the char from thermal degradation. ${ }^{41}$ The high char yields of these polymers can be ascribed to their chemical structure, which has high aromatic content. ${ }^{42}$ Obviously, the data from thermal analysis shows that these polymers have fairly high thermal stability.

3.3d Optical behaviour: To investigate the optical behaviour of resulting polymers, their solutions with concentration of $10^{-5} \mathrm{~mol} / \mathrm{l}$ in DMF are separately prepared and then exposed to UV-vis light. The absorption edge value $\left(\lambda_{0}\right)$ of all the polymers are determined in the range 367-380 $\mathrm{nm}$ and the maximum absorption wavelength $\left(\lambda_{\max }\right)$ appeared in the range $275-302 \mathrm{~nm}$. The absorption spectra of all these polymer solutions are

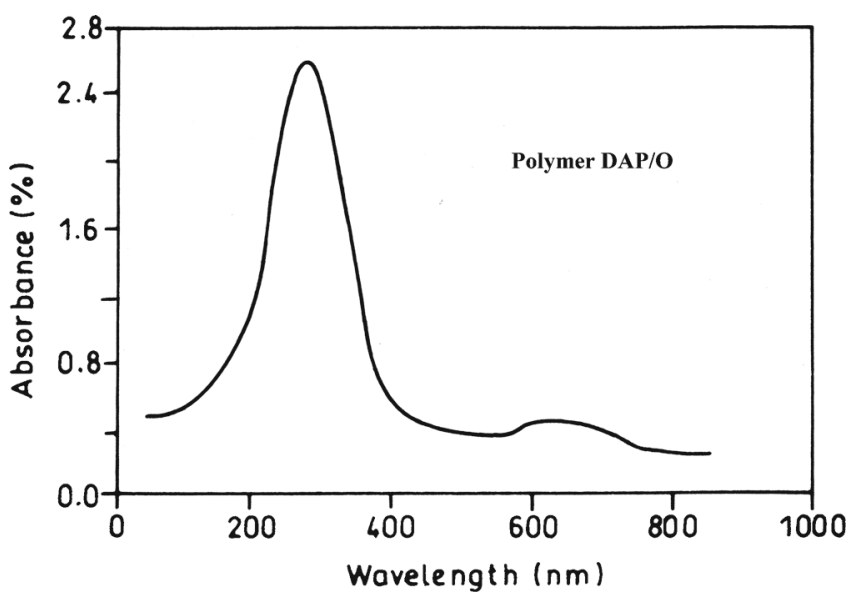

Figure 8. UV-Vis absorption spectrum of DAP/O. 
Table 5. Film characteristics and optical properties of resulting polyamideimides.

\begin{tabular}{lccl}
\hline Polymer & $\lambda_{\text {max }}^{\mathrm{a}}(\mathrm{nm})$ & $\lambda_{\mathrm{o}}^{\mathrm{b}}(\mathrm{nm})$ & \multicolumn{1}{c}{ Film quality $^{\mathrm{c}}$} \\
\hline DAP/O & 289 & 376 & Transparent, flexible, cream \\
DAP/N & 282 & 380 & Transparent, slightly brittle, yellow \\
DAP/B & 302 & 367 & Transparent, flexible, pale brown \\
DAS/O & 281 & 379 & Transparent, flexible, cream \\
DAS/N & 275 & 370 & Transparent, slightly brittle, yellow \\
DAS/B & 279 & 375 & Transparent, flexible, pale brown
\end{tabular}

\footnotetext{
a Obtained from the diluted solutions with polymer concentration of $10^{-5} \mathrm{~mol} / \mathrm{l}$ in DMSO.

${ }^{\mathrm{b}}$ Cut off wavelength at which the light transmittance from thin film becomes below $1 \%$.

${ }^{\mathrm{c}}$ Films were casted by slow evaporation of polymer solution in DMSO.
}

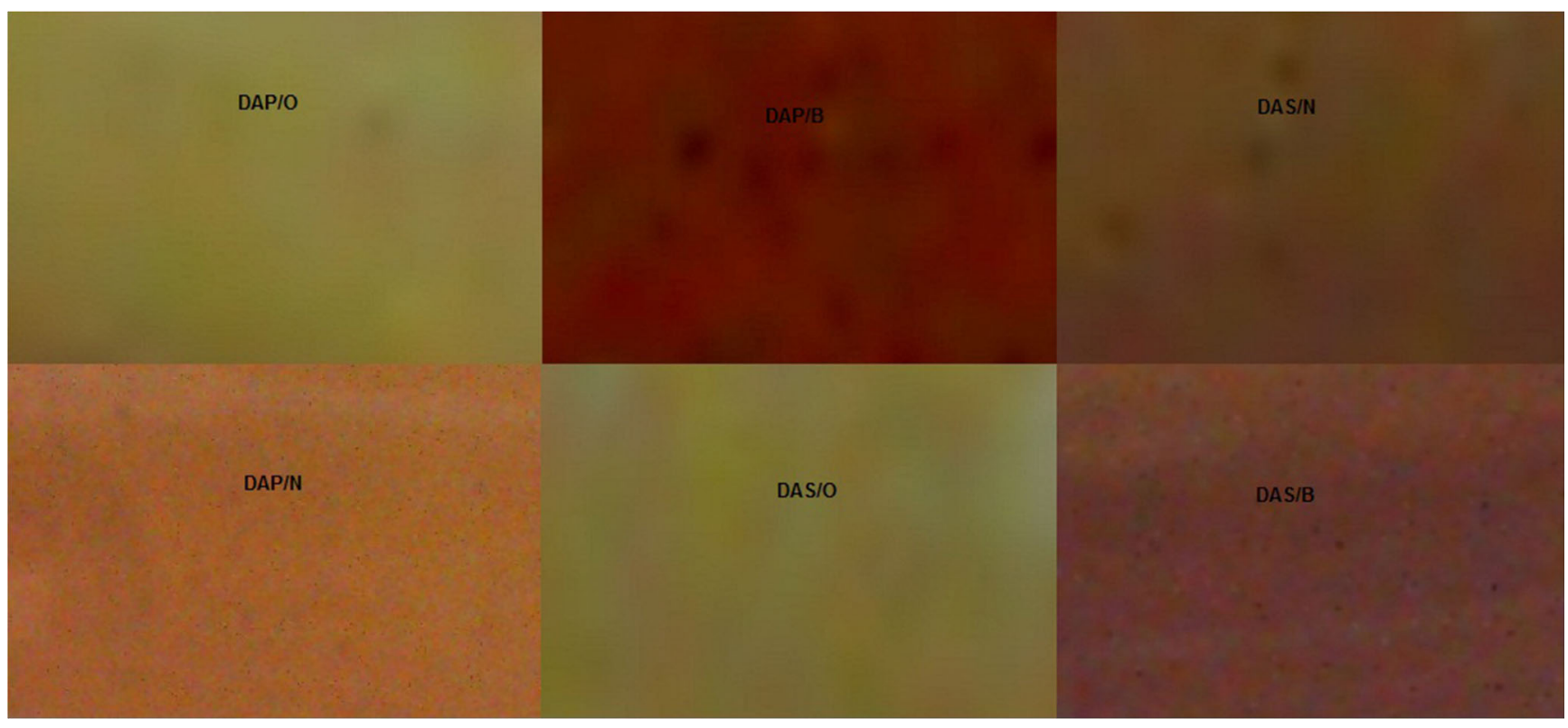

Figure 9. Images of all polymeric films.

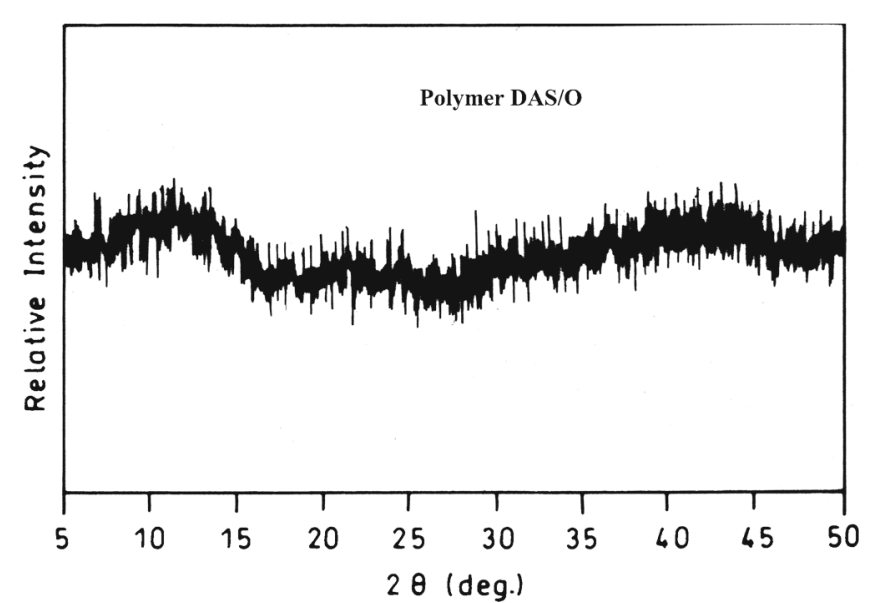

Figure 10. Wide angle X-ray diffractograms of DAS/O. nearly identical with each other. The results obtained clearly show that these polymeric solutions have low colour intensity and high level of optical transparency in UV-vis light region. An UV-vis absorption spectrum of polymer, DAP/O is shown in figure 8 and values of $\lambda_{\mathrm{o}}$ obtained from the diluted solutions of polymers are given in table 5 . The images of all polymeric films are shown in figure 9.

3.3e WAXD studies: The crystallinity of the PAIs was examined by WAXD analysis with graphitemonochromatized radiation, with $2 \theta$ ranging from $5^{\circ}$ to $50^{\circ}$ using the polymer films. Wide angle X-ray 
diffractogram of polymer, DAS/O is represented in figure 10 . Broad peaks are observed in the wide angle $\mathrm{X}$-ray diffraction curve, indicating the absence of crystallinity in resulting polymers. The unsymmetrical kinky $\mathrm{Si}-\mathrm{O}-\mathrm{Ph}$ or/ $(\mathrm{Ph})_{3} \mathrm{P}=\mathrm{C}$ groups and bulky oxy phenyl or/ naphthalene or/ benzophenone flexible chains might inhibit the polymer chain packing and interaction forces, therefore, resulting in lack of crystalline morphology. The amorphous nature of the polymers would endow a good solubility.

\section{Conclusions}

Two novel diamines, 3-[bis-(3-aminophenyl)phosphinoyl)-phenyl]-3-(triphenyl-phosphoranylidene)pyrrolidene-2,5-dione (DAP) and bis-(5-aminonaphthalene-1-yl) dimethyl silane (DAS) are successfully synthesized. A series of aromatic polyamideimides have been readily prepared from synthesized diamines and various diimide-diacids via direct phosphorylation polycondensation. The introduction of bulky silicon and phosphorus containing phenylene groups in polymeric chain can increase solubility in organic solvents and disrupt the co-planarity of aromatic units in packing of chain. These polymers demonstrate nice balance of properties comprising excellent thermal stability with moderate glass transition temperature. All the low coloured polymeric films are significantly flexible and show high optical transparency in UV-Vis region. The high char yield of these polymers may be due to incorporation of silicon and phosphorus containing phenyl groups. The incorporation of flexible groups prevented polymeric chain from close packing and is responsible for their amorphous nature.

\section{Acknowledgements}

The author (S. Agrawal) wishes to express the gratitude to Guru Gobind Singh Indraprastha University, New Delhi for providing financial support in the form of IPRF (Indraprastha Research Felloship).

\section{References}

1. Marinovic-Cincovic M, Babic D, Dzunuzovic E, Popov-Pergal K and Rancic M 2007 Polym. Degrad. Stabil. 921730

2. Leung C L, Ghaffarian R and Leung K C 1997 Polym. Degrad. Stabil. 5811

3. urRehman S, Li P, Zhou H W, Zhao X G, Dang G D and Chen C H 2012 Polym. Degrad. Stabil. 971581

4. Babanzadeh S, Mahjoub A R and Mehdipour-Ataei S 2010 Polym. Degrad. Stabil. 952492
5. Musto P, Ragosta G, Scarinzi G and Mascia L 2004 Polymer 454265

6. Tao L, Yang H, Liu J, Fan L and Yang S 2009 Polymer 506009

7. Behniafar H and Sefid-girandehi N 2011 J. Fluor. Chem. 132878

8. Hasegawa M and Nomura R 2011 React. Funct. Polym. 71109

9. Liaw D-J, Wang K-L, Huang Y-C, Lee K-R, Lai J-Y and Ha C-S 2012 Prog. Polym. Sci. 37907

10. Hong S P, Kim I-C, Tak T and Kwon Y-N 2013 Desalination 30918

11. Huang Y-C, Lin J-H, Tseng I-H, Lo A-Y, Lo T-Y, Yu H-P, Tsai M-H, Whang W-T and Hsu K-Y 2013 Compos. Sci. Technol. 87174

12. Mallakpour S and Dinari M 2013 Appl. Clay Sci. 75-76 67

13. Kovalev M K, Kalinina F, Androsov D A and Cho C 2013 Polymer 54127

14. Kim S D, Lee S, Heo J, Kim S Y and Chung I S 2013 Polymer $\mathbf{5 4} 5648$

15. Lin C H, Chang S L, Peng L A, Peng S P and Chuang Y H 2010 Polymer 513899

16. Yang F, Li Y, Bu Q, Zhang S, Ma T and Zhao J 2010 Polym. Degrad. Stabil. 951950

17. Shockravi A, Abouzari-Lotf E, Javadi A and Atabaki F 2009 Eur. Polym. J. 451599

18. Liaw D-J and Chen W-H 2006 Polym. Degrad. Stabil. 911731

19. Behniafar H and Abedini-pozveh A 2011 Polym. Degrad. Stabil. 961327

20. Liu C, Wang J, Lin E, Zong L and Jian X 2012 Polym. Degrad. Stabil. 97460

21. Comesana-Gandara B, Calle M, Jo H J, Hernandez A, Campa J G D, Abajo J D, Lozano A E and Lee Y M 2014 J. Memb. Sci. 450369

22. Liu J, Zhang Q, Xia Q, Dong J and Xu Q 2012 Polym. Degrad. Stabil. 97987

23. Behniafar H, Beit-Saeed A and Hadian A 2009 Polym. Degrad. Stabil. 941991

24. Liu Y-L and Tsai S-H 2002 Polymer 435757

25. Song G, Zhang Y, Wang D, Chen C, Zhou H, Zhao X and Dang G 2013 Polymer 542335

26. Higashi F, Ogata S-I and Aoki Y 1982 J. Polym. Sci. A: Polym. Chem. 202081

27. Tao Z, Yang S, Chen J and Fan L 2007 Eur. Polym. J. 43 1470

28. Hamciuc E, Hamciuc C, Bruma M and Schulz B 2005 Eur. Polym. J. 412989

29. Bazzar M, Ghaemy M and Alizadeh R 2012 Polym. Degrad. Stabil. 971690

30. Hamciuc E, Hamciuc C and Bruma M 2007 Eur. Polym. J. 434739

31. Sponton M, Mercado L A, Ronda J C, Galia M and Cadiz V 2008 Polym. Degrad. Stabil. 932025

32. Zhang W, Li X, Jiang Y and Yang R 2013 Polym. Degrad. Stabil. 98246

33. Ren H, Sun J, Wu B and Zhou Q 2007 Polym. Degrad. Stabil. 92956

34. Liu Y L, Hsiue G H, Lee R H and Chiu Y S 1997 J. Appl. Polym. Sci. 63895

35. Lin C H 2004 Polymer 457911 
36. Agrawal S and Narula A K 2013 Polym. Bull. 703241

37. Liu C, Li X, Xu J and Jian X 2011 Eur. Polym. J. 47 1852

38. Jeong K U, Kim J-J and Yoon T-H 2001 Polymer 42 6019

39. Wu C S, Liu Y L and Chiu Y S 2002 Polymer 434277
40. Qian L-J, Ye L-J, Xu G-Z, Liu J and Guo J-Q 2011 Polym. Degrad. Stabil. 961118

41. Wang X, Hu Y, Song L, Xing W and Lu H 2010 J. Polym. Sci.: Part B: Polym. Phys. 48693

42. Behniafar H and Mohammadparast-delshaad S 2012 Polym. Degrad. Stabil. 97228 